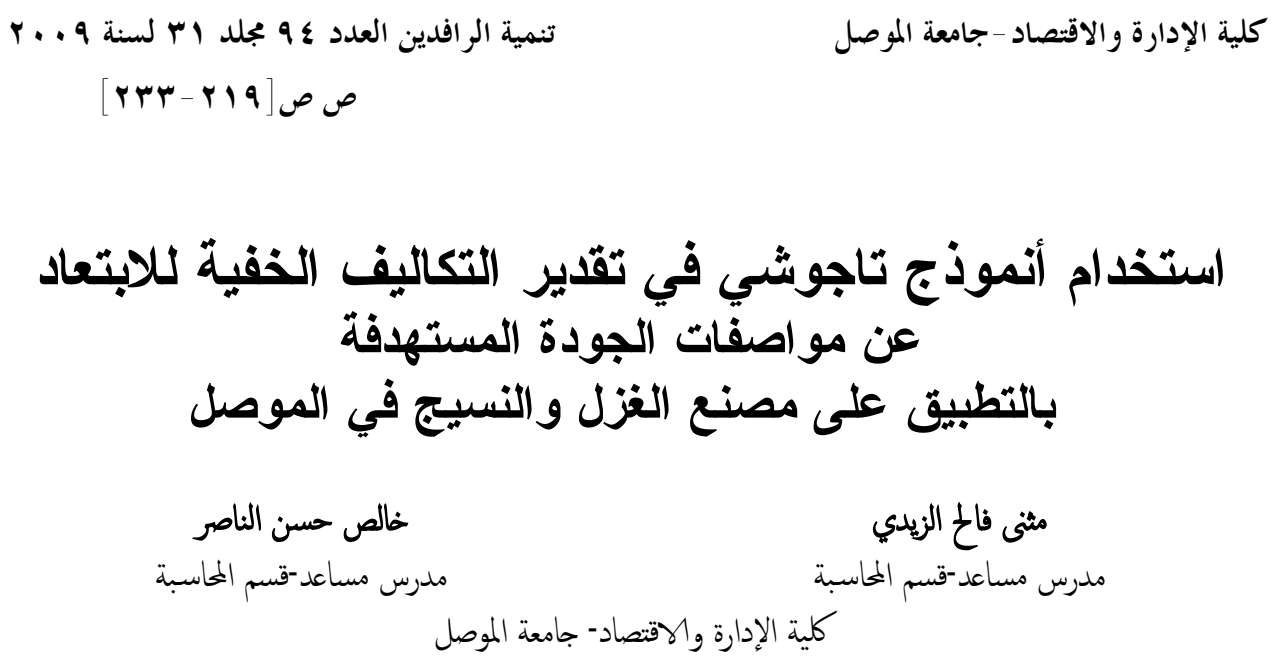

Khalisaljarjary@yahoo.com

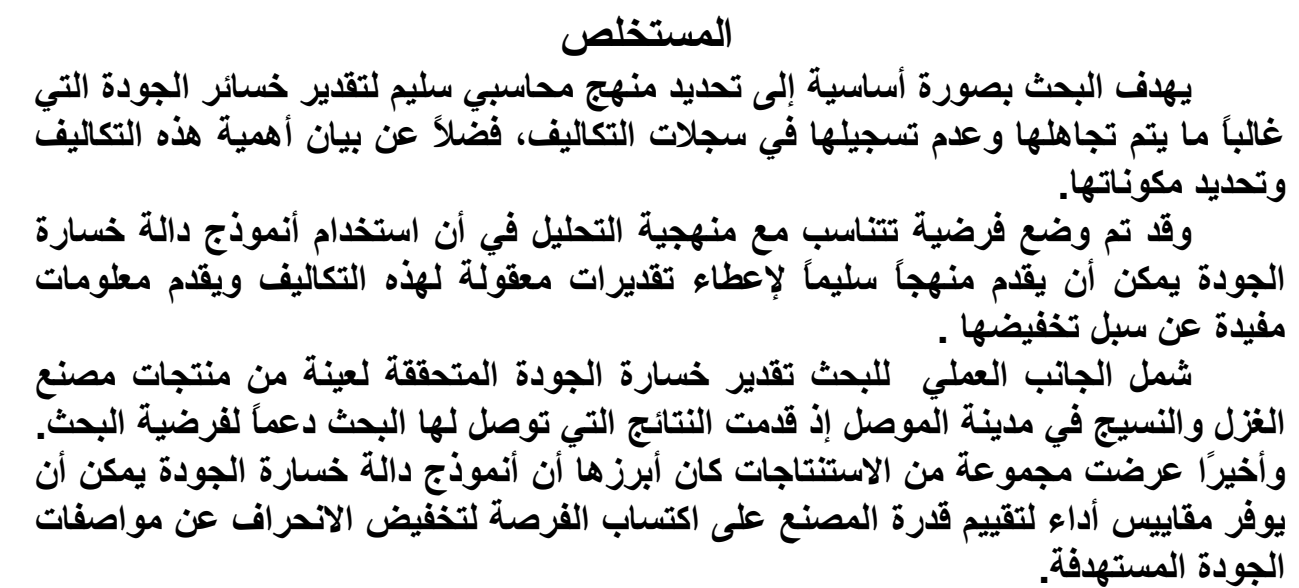

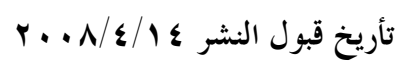

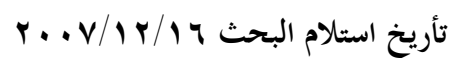




\title{
Using of Taguchi Model in Estimating Hidden Cost of Deviation from Target Quality Specifications with the Application on the Textile Factory in Mosul
}

\author{
Muthana F. Al-Zaidy \\ Assistant Lecturer \\ Department of Accountancy \\ University of Mosul
}

\author{
Khalis H. Al-Nasser \\ Assistant Lecturer \\ Department of Accountancy \\ University of Mosul
}

\begin{abstract}
The present paper primarily concerned with determining an appropriate accounting approach for estimate the Quality Loss which is often ignored and unrecorded in cost records. Moreover, the article aims at explaining the importance of the costs after identifying components of these costs. The major hypothesis supposed that the use of Quality Loss Function Model can provide a procedural method to present appropriate estimations for those costs and provide useful information to reduce those costs. The practical part of the paper included estimating the Quality Loss for samples of Mosul factory for spinning and weaving products. The results obtained to support the hypothesis of the study. The study concluded that the Quality Loss function model provides performance measures to evaluate the factory ability in gaining opportunity of reducing deviation from the targeted quality.
\end{abstract}

المقدمة

في عالم تسوده المنافسة أصبح فيه اكتساب الفرصة في الحصول على المبن زبائن

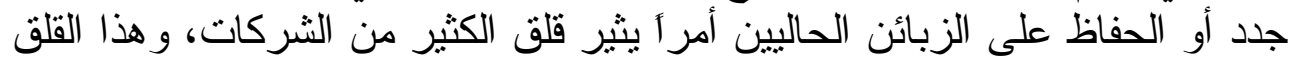

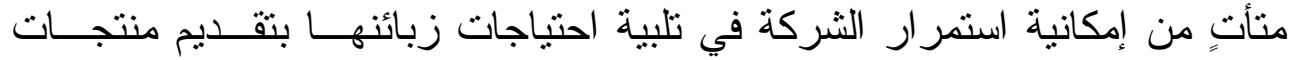

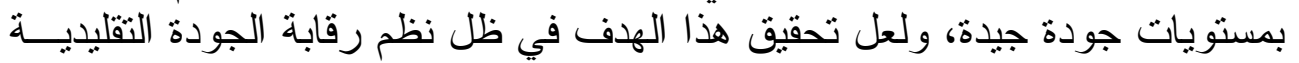

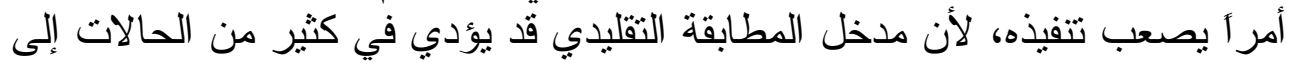

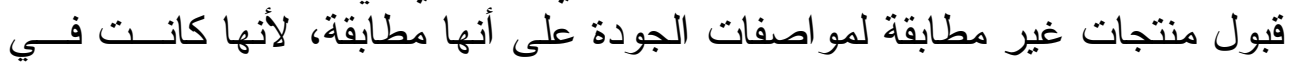

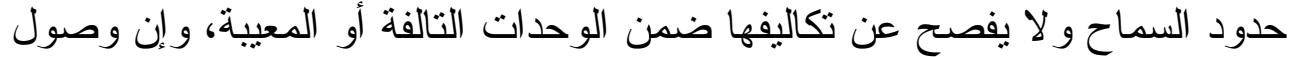

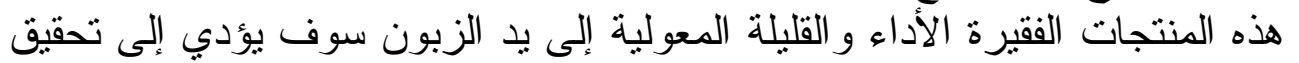

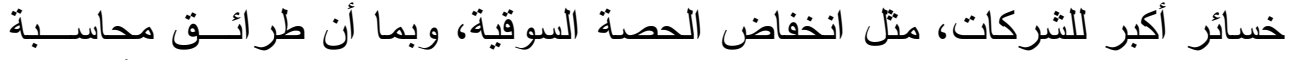
التكاليف التقليدية غير مصممة لقياس منل هذه الخسارة فقد طور تاجوشي أســلـوباً

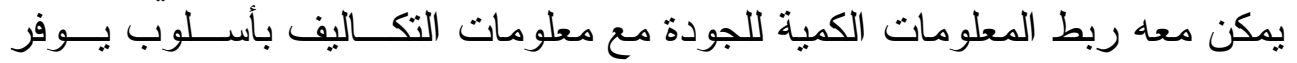
منهجية سليمة لإعطاء تقدير ات معقولة عن تكاليف الابتعاد المحتملة عن مو اصفات الجودة المستهدفة و الذي يعد ضرورياً لتحقيق رقابة فاعلة على على هذه الكلف . 
تتلخص مشكلة البحث في قصور نظم التكاليف التقليدية عن توفير تقديرات

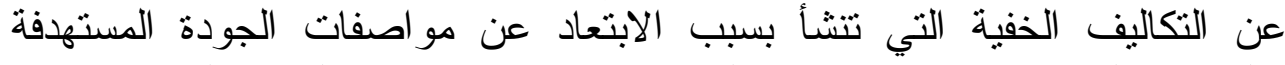
و الخسائر الناتجة عن عدم اكتساب الفرصة في انجاز مستوى الجودة المستهدف.

هاف البحث البحث إلى استخدام أنموذج تاجوشي في تقدير تكاليف الابتعاد عن

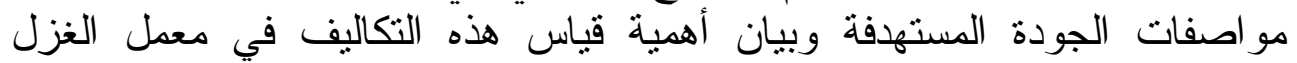
و النسيج في مدينة الموصل وتوفير بيانات عن قدرة وكفاءة المعطل في اكتساب الكياب الفرصة. في في الفي

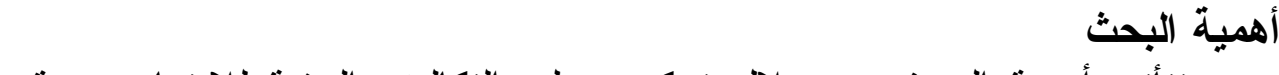

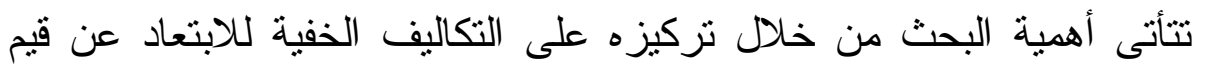

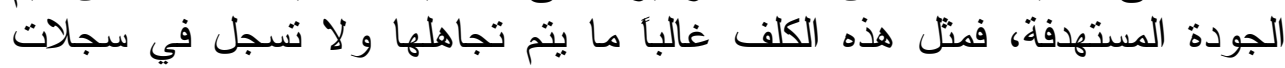
التكاليف لصعوبة قياسها.

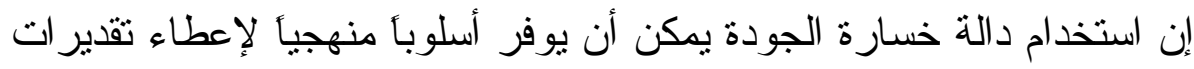

فرضية البحث

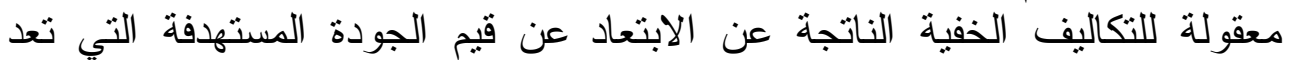
ضرورية لتحقيق رقابة فاعلة على هذه الكلف.

لتحقيق هدف البحث واختبار فرضيته، نم الاعتماد على المنهج الوصفي في البه

منهج البحث

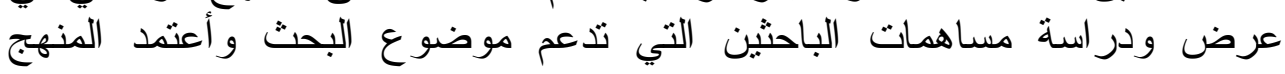
التحليلي في در اسة مجالات النطبيق على عينة البحث.

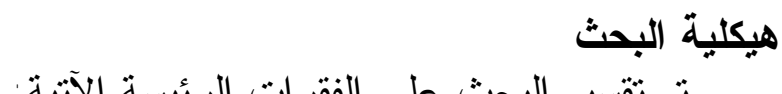

$$
\begin{aligned}
& \text { تم تقسيم البحث على الفقرات الرئيسة الآتية: } \\
& \text { أو لا: فلسفة تاجوشي في مجال إدارة الجودة. } \\
& \text { ثانياً: دالة خسارة الجودة لتاجئ لتاجوشي. }
\end{aligned}
$$

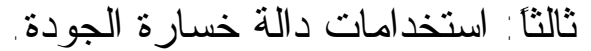

$$
\begin{aligned}
& \text { رابعأ: قياس خسارة الجودة في مصنع الغزل و النسيج في الموصل . }
\end{aligned}
$$




\section{أولاً - فلسفة تاجوشي في مجال إدارة الجودة}

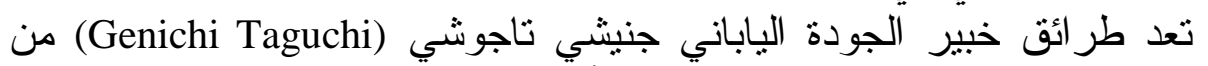

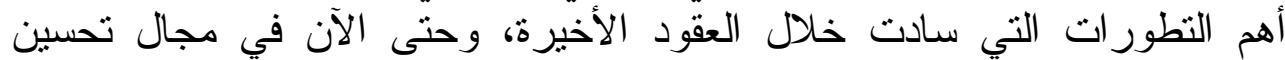

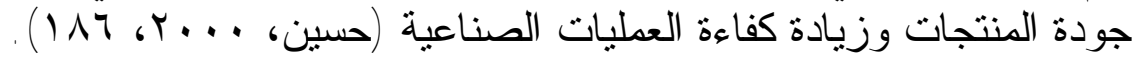

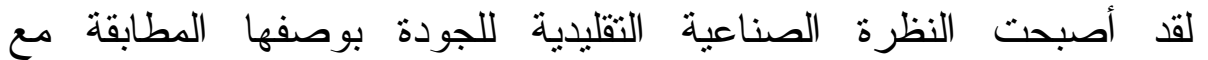

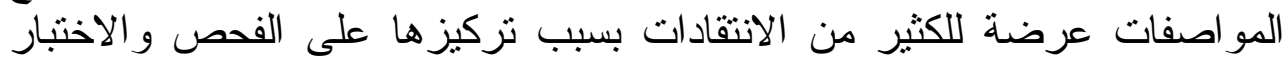

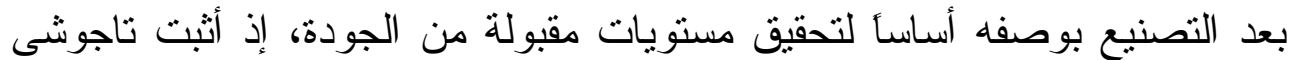

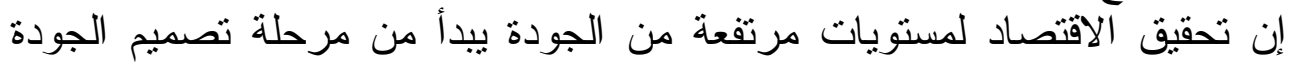

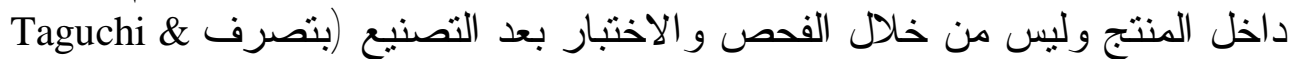

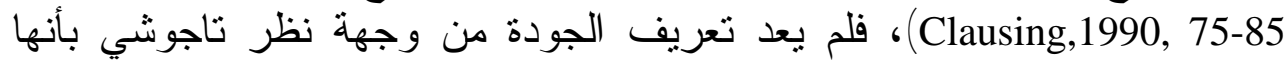

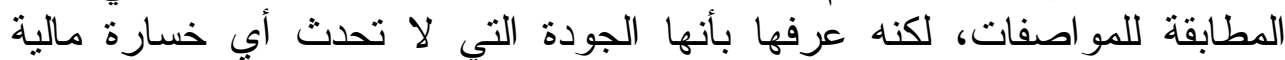

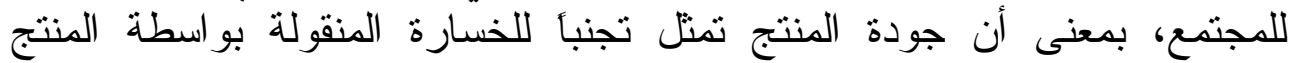

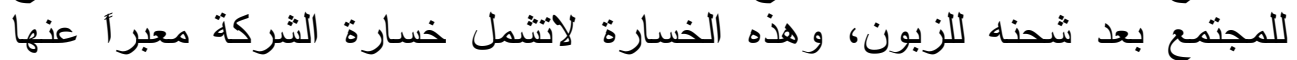

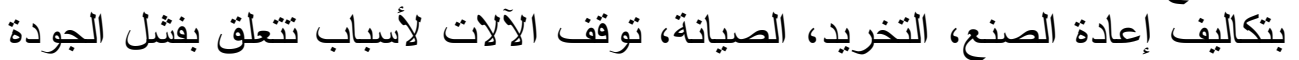

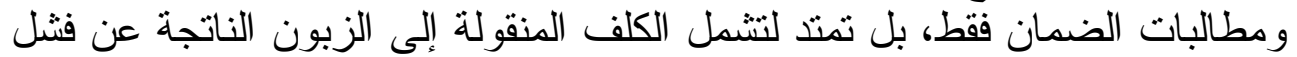

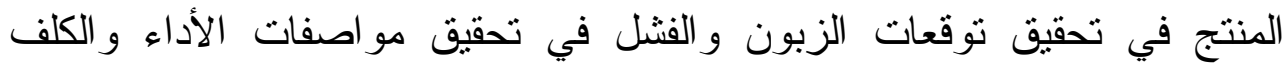
الاجتماعية الأخرى كالتلوث فثلات (Dale,1994,440).

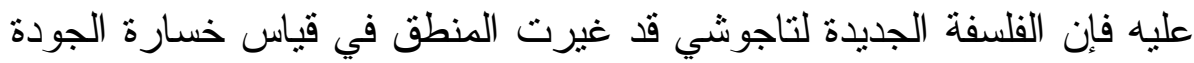

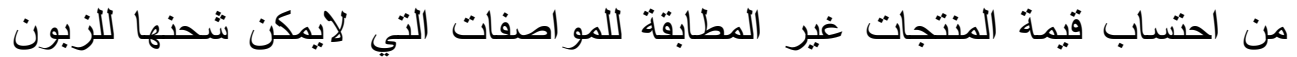

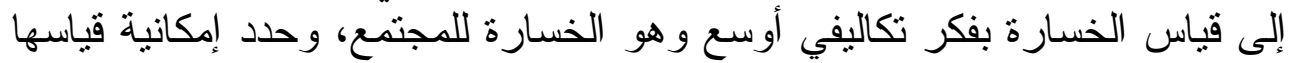
من خلال ربطها بمواصفات المنتجات القابلة للقياس الكمي \& Schonberger \&

.Kond, 1997, 82)

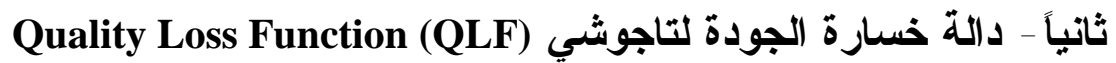
ساعدت الأفكار التي قدمها تاجوشى في في مجال تصال تصميم الجودة عن تطويره

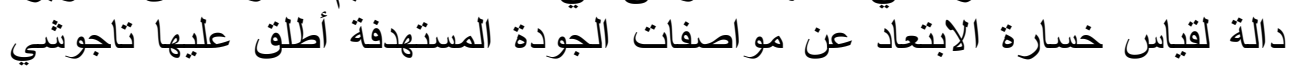

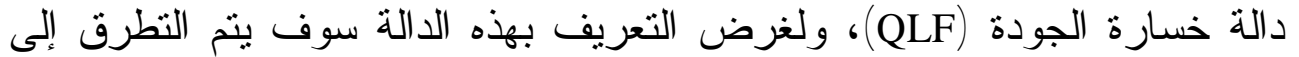

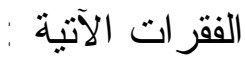

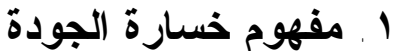

يقصد بخسارة الجودة إجمالي الخسارة التي تتحملها الثركة و التي تعود

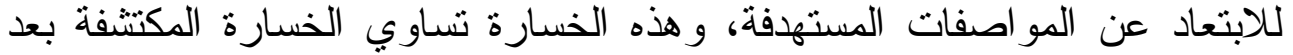

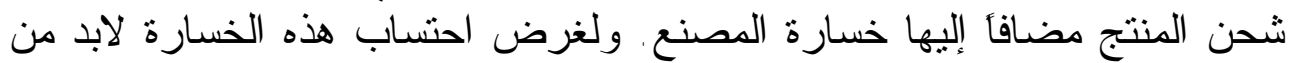

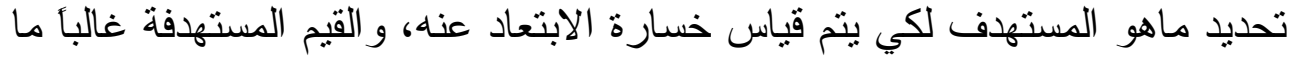

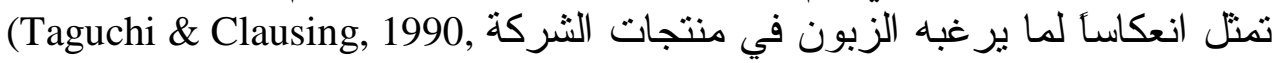




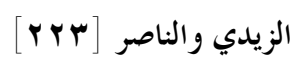

يفترض الأنموذج التقليدي لتكاليف الجودة أن هذه الخسارة لا تحدث إلا إذا

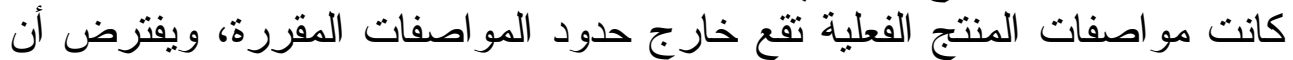

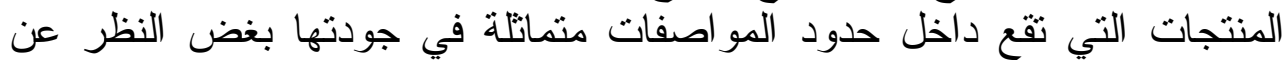

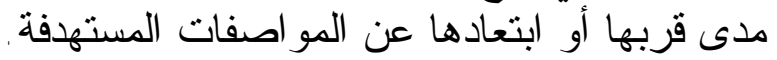
في حين أن الأنموذج الحديث لتكاليف الجودة يتفق مع أنموذج تاجوشي في التئي أن الخسارة تحدث بمجرد انحر اف المنتج عن المو اصفات المستهدفة، و وأنه يميز

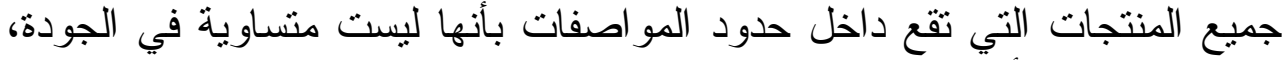

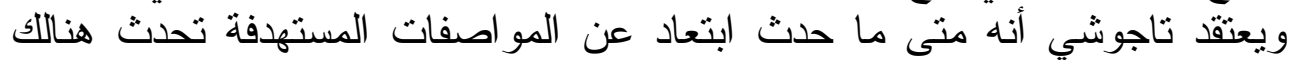

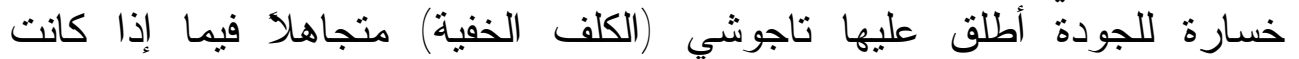
المنتجات تقع داخل حدود المو اصفات أم خارجها (Albright \&Roth, 1992, 29)

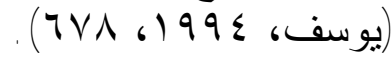
يوضح الشكل الآتي مقارنة بين الأنموذجين التقليدي والحديث في تعريف خسارة الجودة.
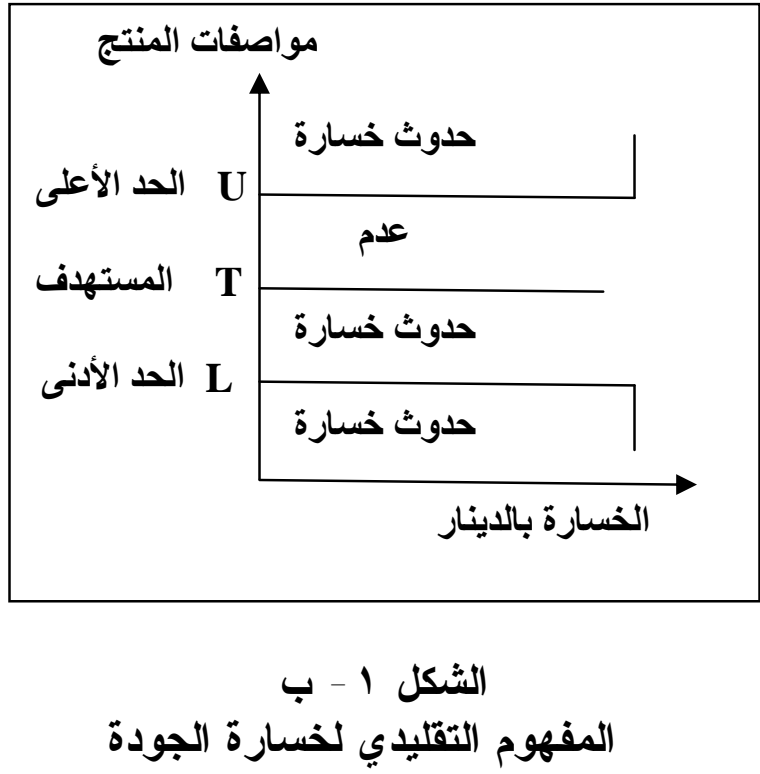

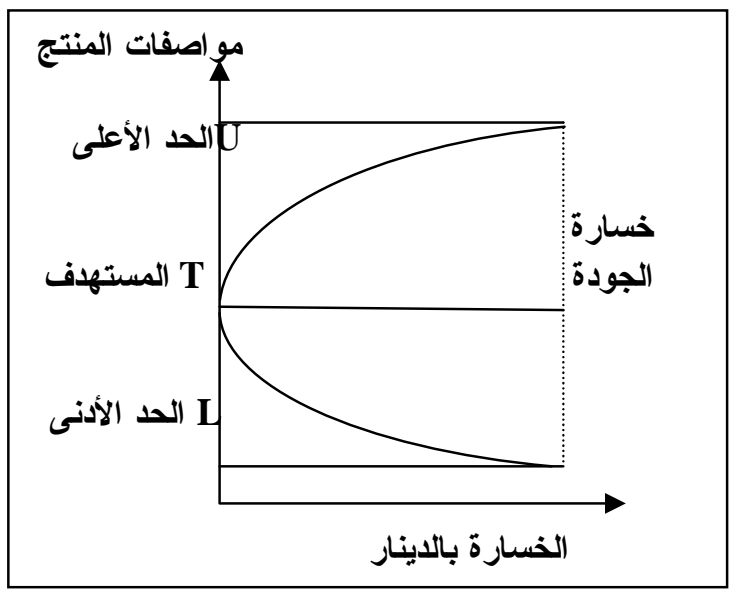

\section{الشكل 1 -أ}

مفهوم تاجوشي لخسارة الجودة

Source: Sedatol,K.L,2003,"The Effect Of Measurement Alternatives On Non- Financial Quality Measures :Forward-Looking Properties", Accounting Review,April:P559 
r r مفهوم تكاليف الجودة الخفية|(*)

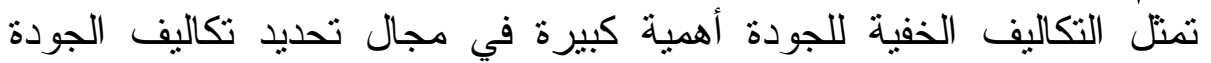

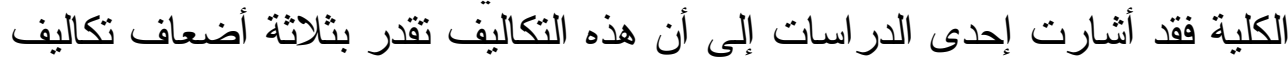

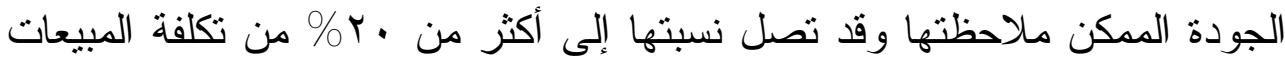

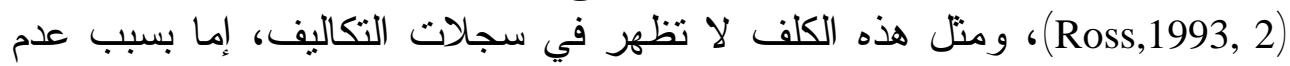

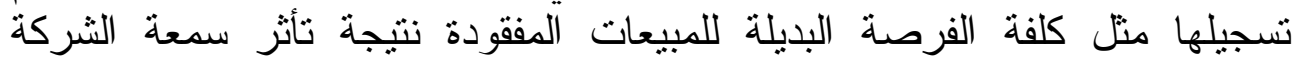

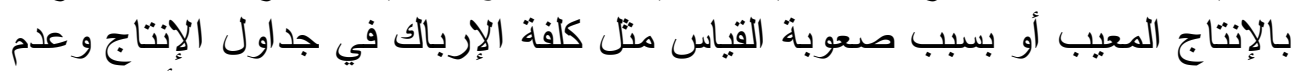

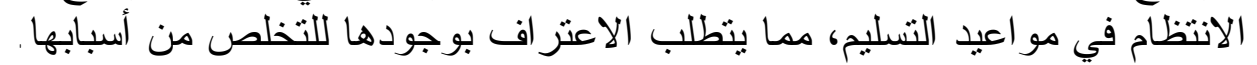

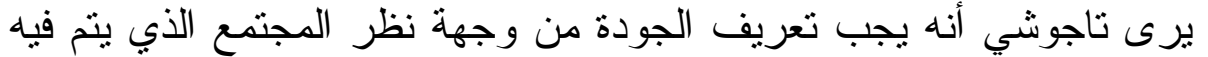

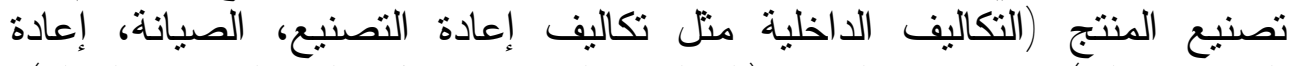
الفحص ...الخ) و واستخدام المنتج (النكاليف الخارجية منل كلفة الفرصة البدايلة الفيلة).

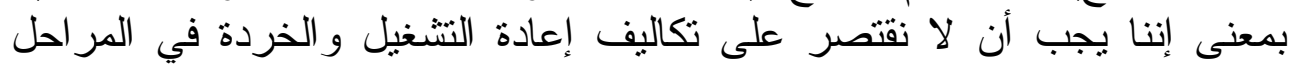
الإنتاجية فقط، ولكن يجب أن نأخذ كلف الإنتاجية المفقودة لعدم الكفاءة الذّي بسيبه

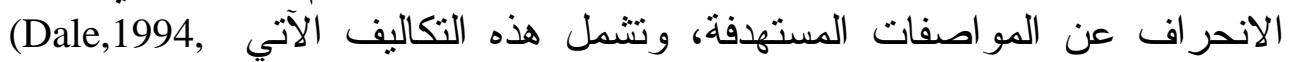
: (217)

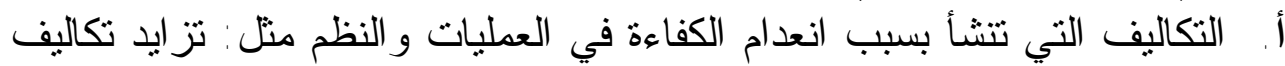

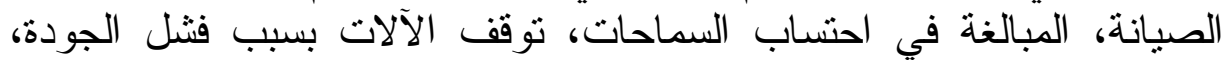

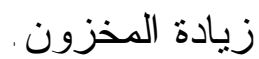

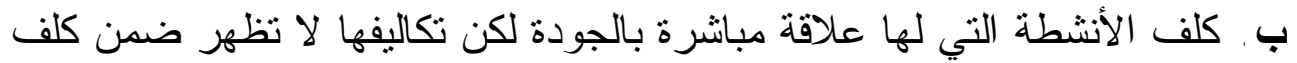

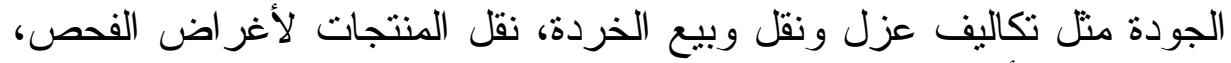

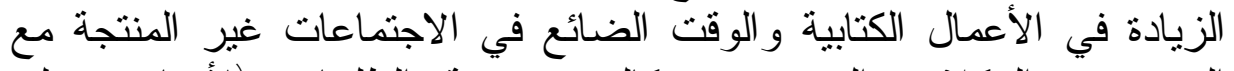

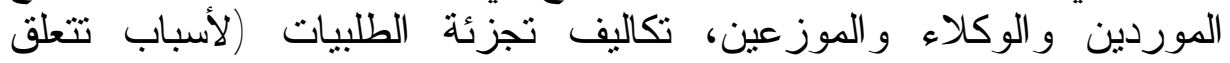
بالجودة) .

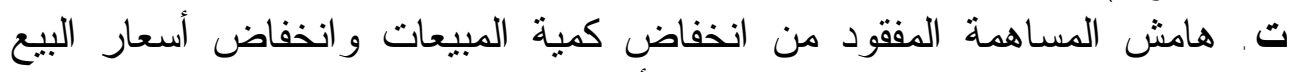

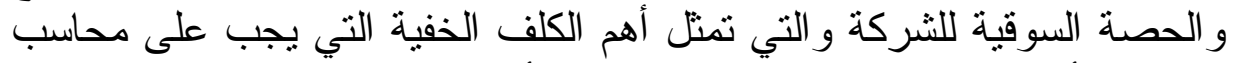

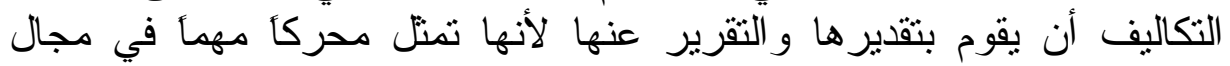
إعداد بر امج تحسين الجودة (Horengren,et.al,2003, 680).

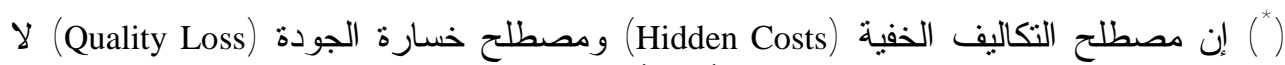

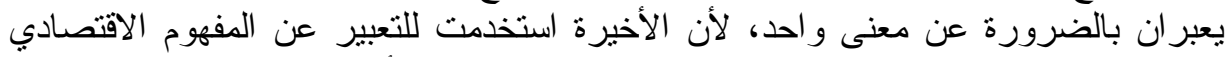

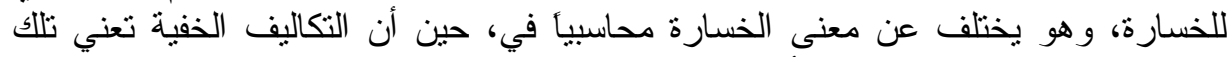

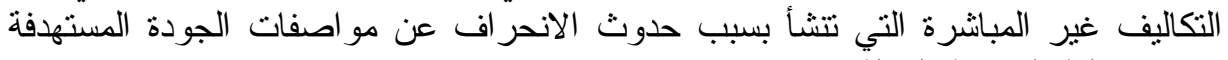
بما فيها كلفة الفرصة البديلة. 


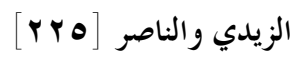

\section{ب بقاير تكاليف الجودة الخفية باستخدام دالة الخسارة}

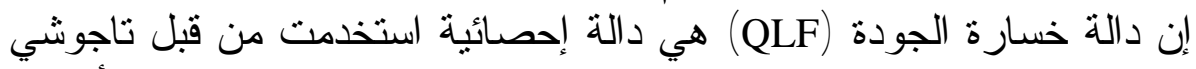

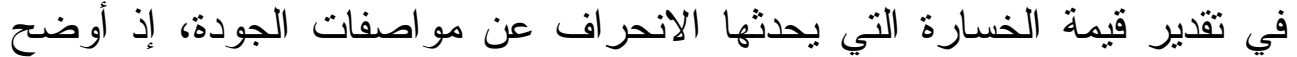

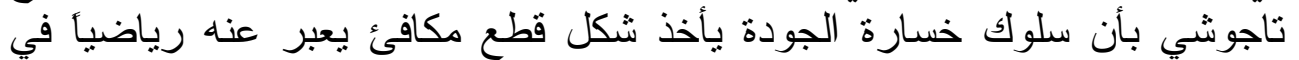

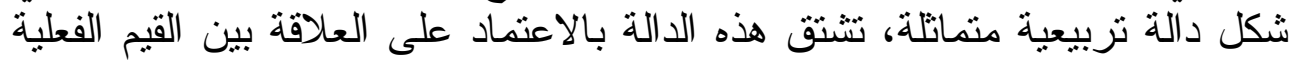

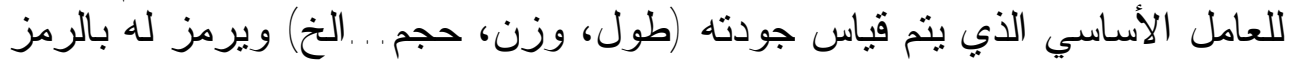

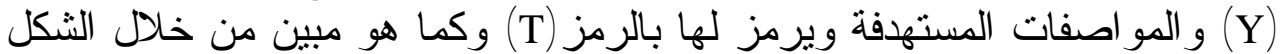
و المعادلات الآتية (يوسف، ع 99 (1)، TV9):

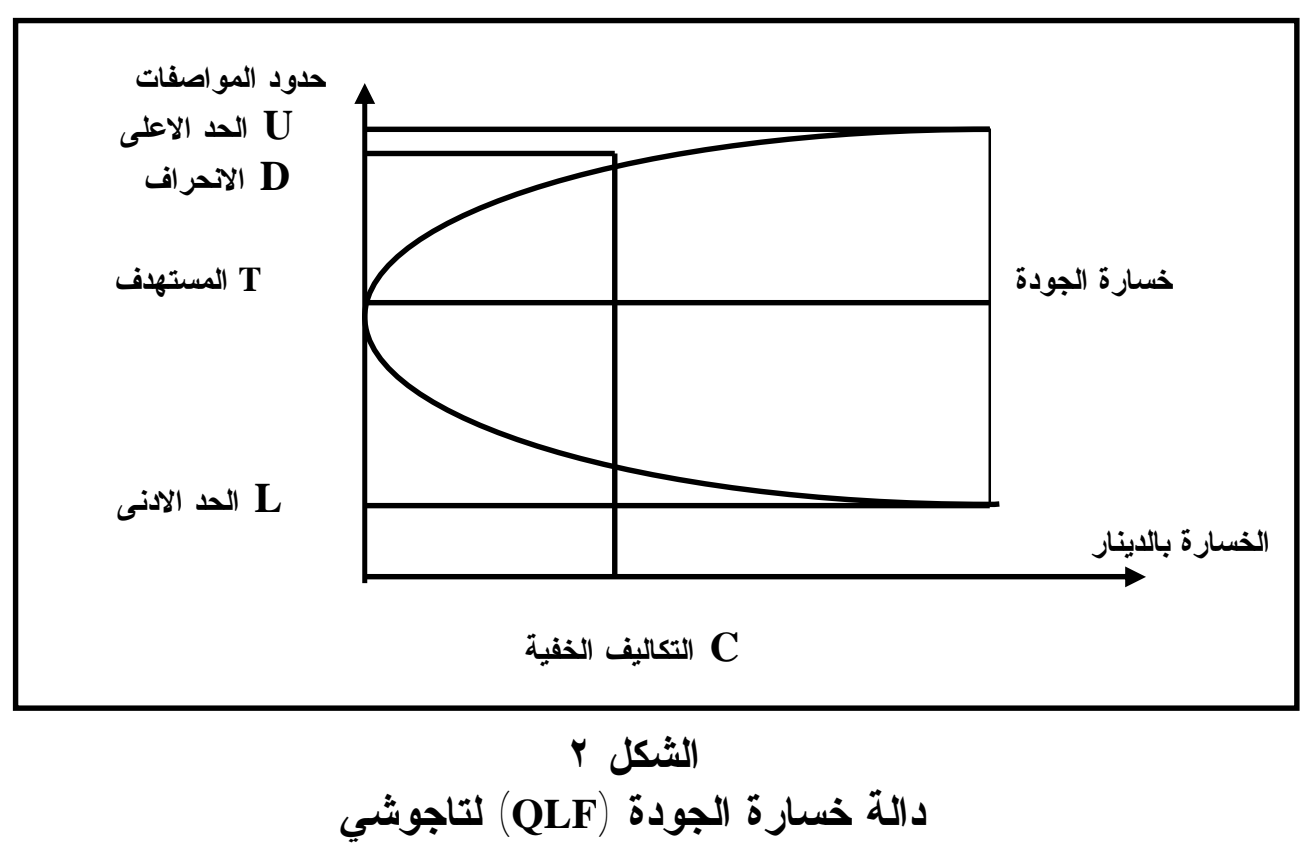

Source: Richard J. Schonberger, Edward M.Kond,1997,"Operation Management: Customer-Focused Principles",P82

ويمكن احتساب قيمة الخسارة رياضياً باستخدام المعادلة الآنية : $\operatorname{Loss}(\mathrm{Y}) \operatorname{avg}=\mathrm{K}\left[\mathrm{S}^{2}+(\mathrm{Y}-\overline{\mathrm{T}})^{2}\right]$

K = تعبر عن أن المعامل الفني الثابت (Constant) الخاص بطبيعة تكلفة العملية

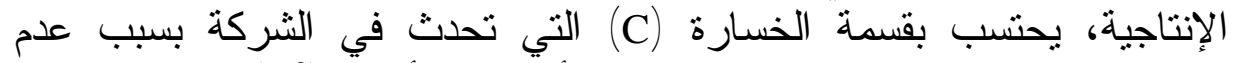

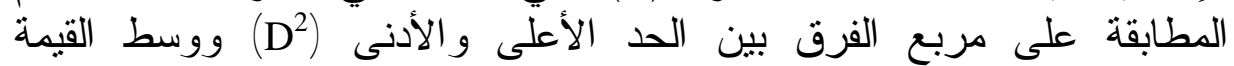
$\mathrm{K}=\left(\mathrm{C} / \mathrm{D}^{2}\right)$ 
وفي حالة عدم تماتل الدالة من حيث إمكانية تحديد الحد الأدنى أو الحد الأعلى للمواصفات المستهدفة فإن قيمة (K) تحسب بالثية بالثكل الآتي وهو ما سيتم

$$
\mathrm{K}=(\mathrm{C} / \mathrm{D})
$$

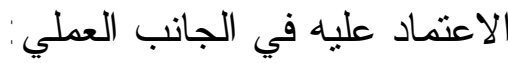

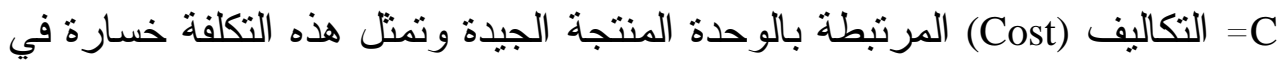

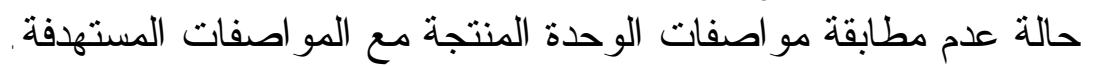
D انحر اف المواصفات (Deviation) عن القيمة القيمة المستهدفة (المسافة من القيمة

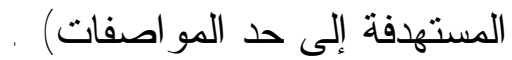

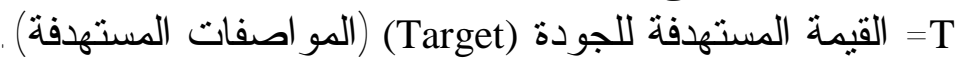
= المتوسط الفعلي للعينة، إذ تمثل (Y) القيمة الفعلية للجودة (المو اصفات الفعلية).

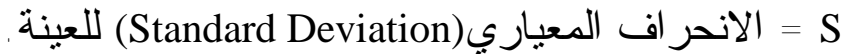

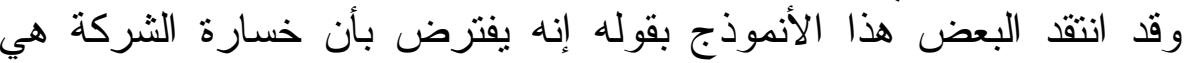

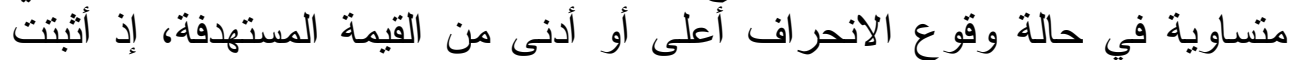

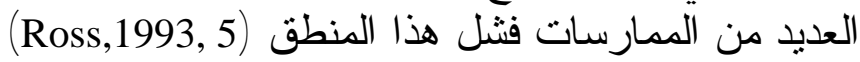

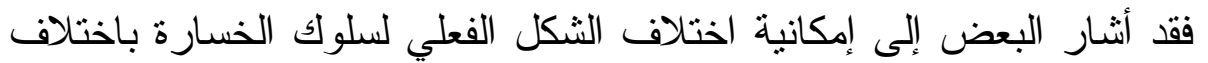

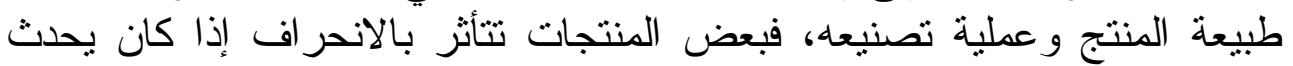

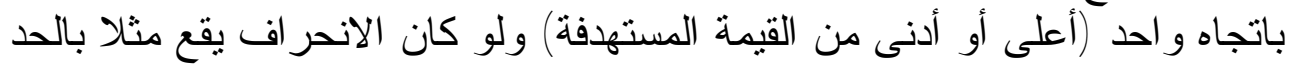

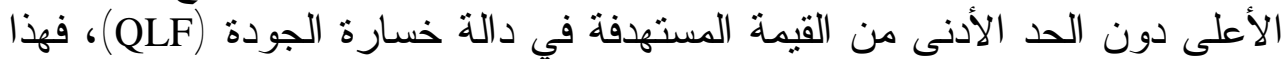

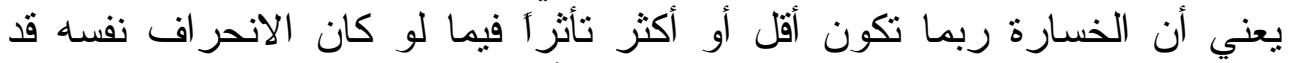

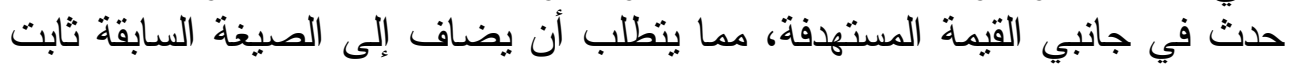

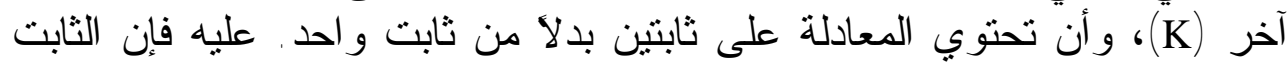

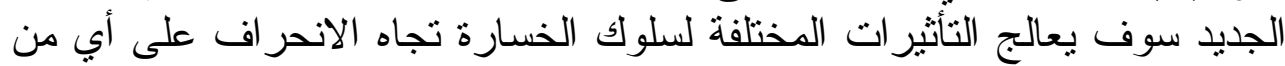

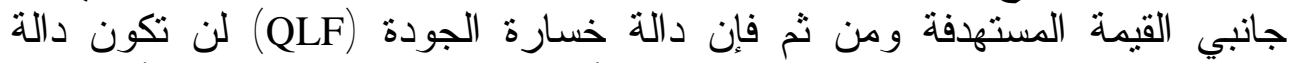

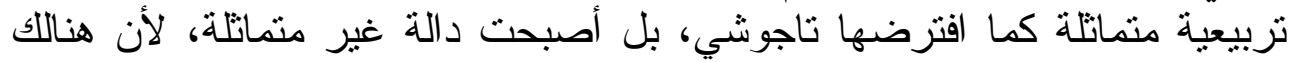

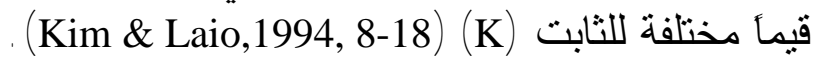

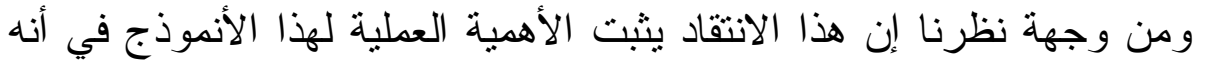

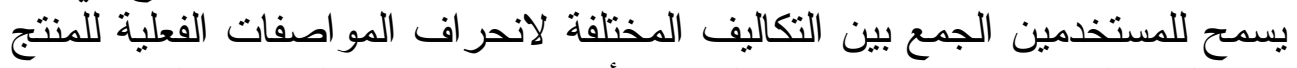

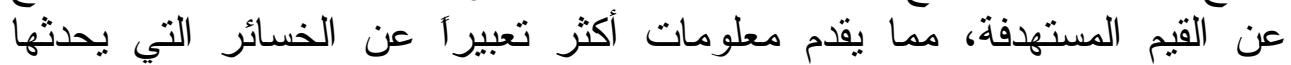
الانحر اف على أي من جانبي القيمة المستهدفة.

(الثاً - استخدامات دالة خسارة الجودة (QLF)

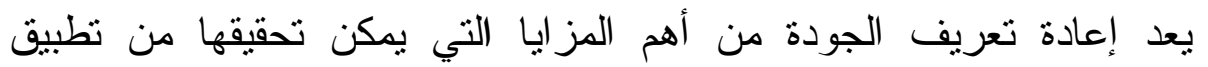

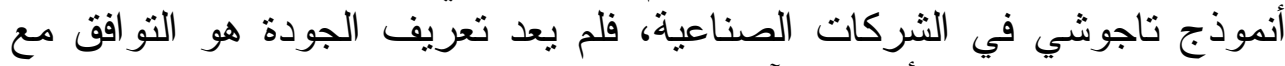

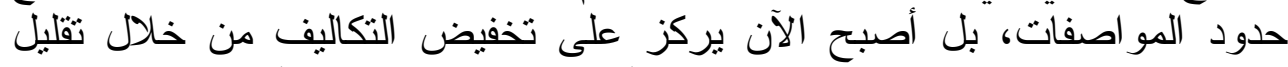

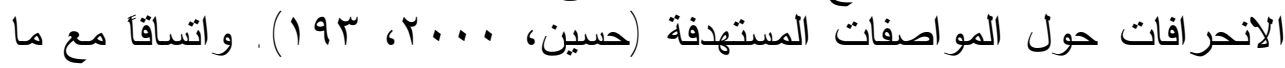




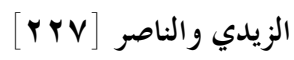

سبق فان هنالك ميزتين أساسيتين يمكن تحقيقهما من تطبيق دالة خسارة الجودة (Albright \& Roth ,1994, 30-34) (QLF)

ا ـ الموازنة بين خسارة الجودة ومواصفات المنتج: يمكن الاستفادة من دالة

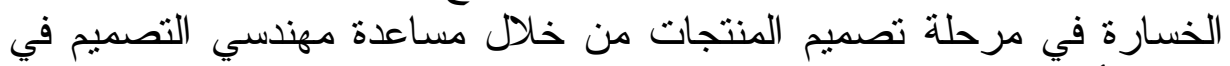

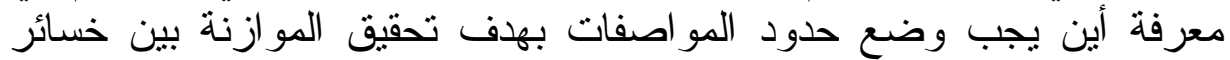

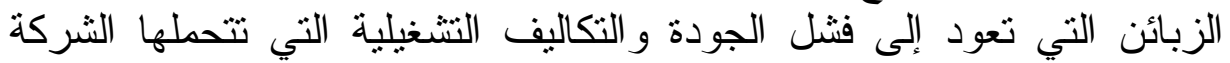

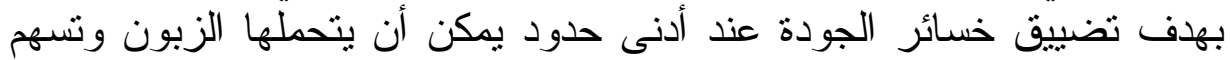

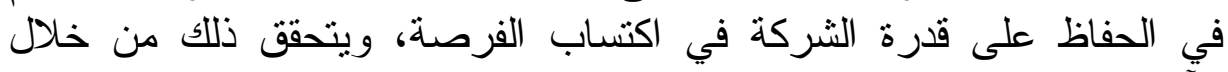

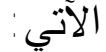

أ. جعل المتوسط الفعلي لمو اصفات الجودة مساو للقيمة المستهدفة .

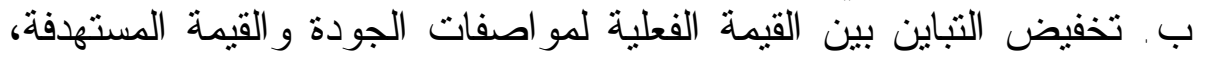
إذا لم يكن تحقيق القيمة المستهدفة هدفأ ممكناً اقتصادياً.

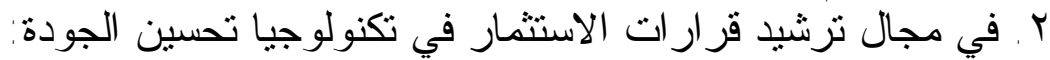

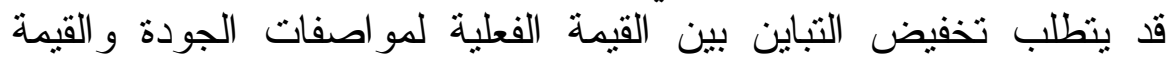

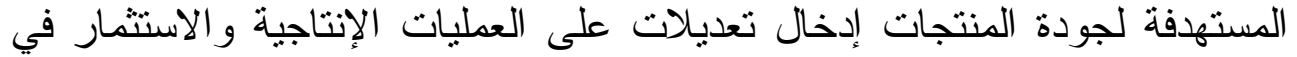

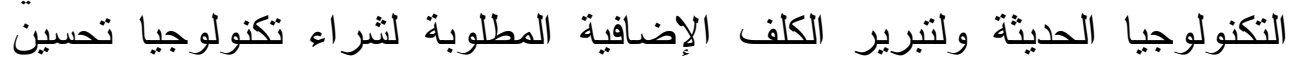

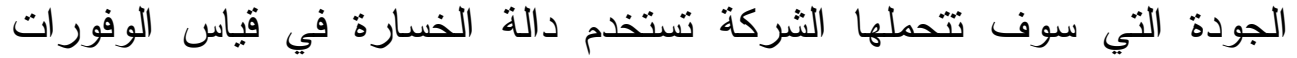
المتحققة من انخفاض كلف الفشل الخارجية نتيجة لتحسن الجودة قياسأ بتكاليف التيف

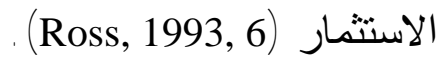

\section{رابعاً - قياس خسارة الجودة في مصنع الغزل والنسيج}

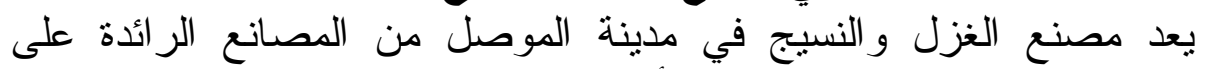

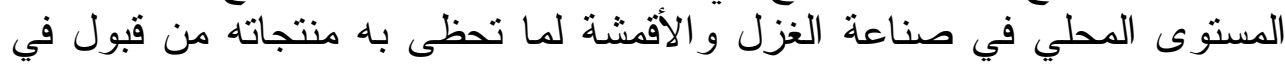

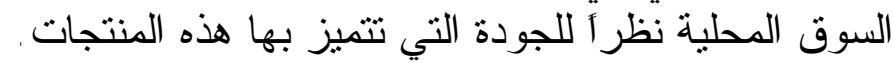

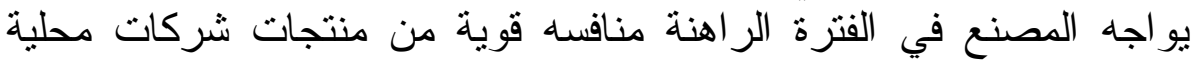

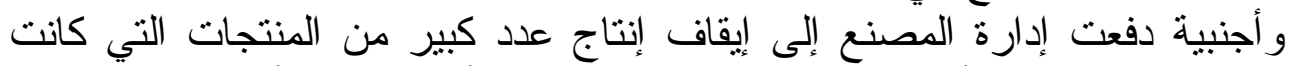

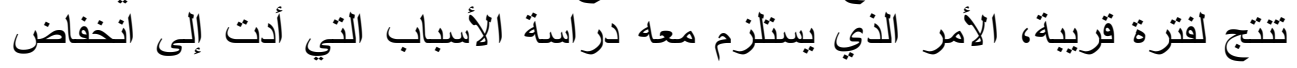

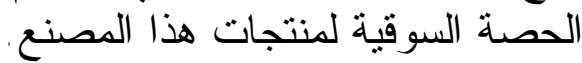
ا ـ مقاييس الجودة في المصنع

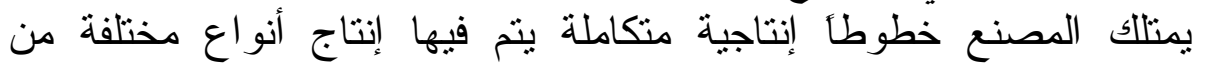

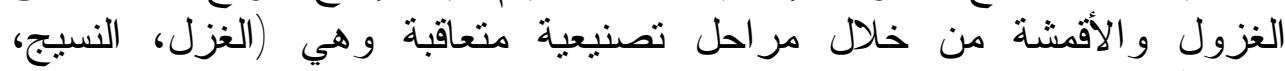

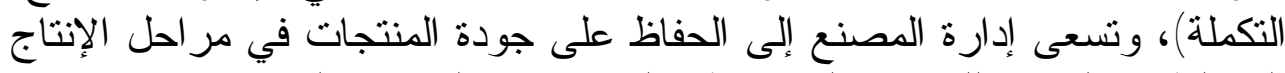

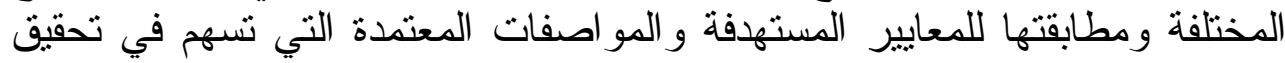

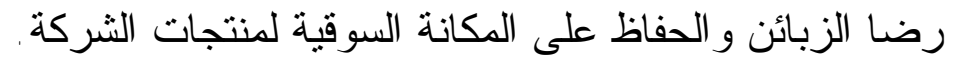

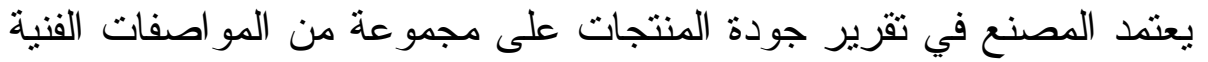

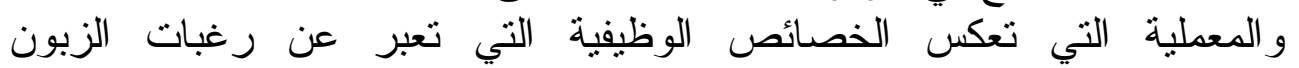




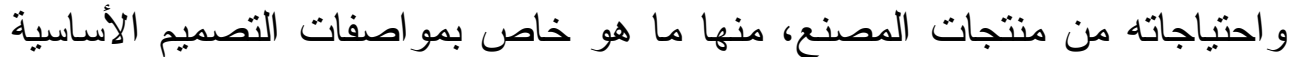

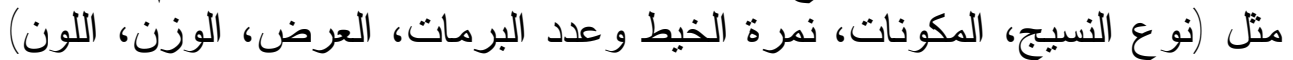

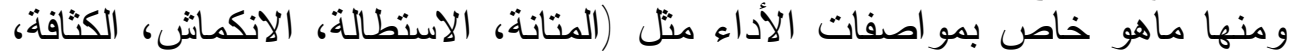

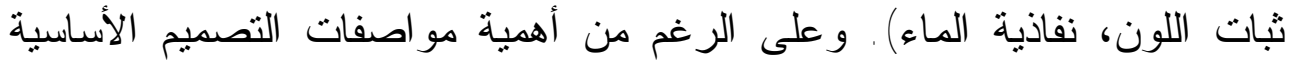

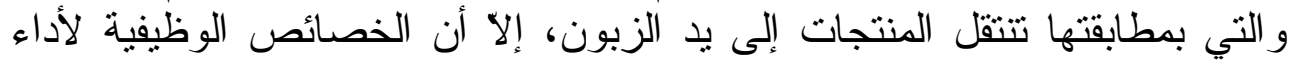

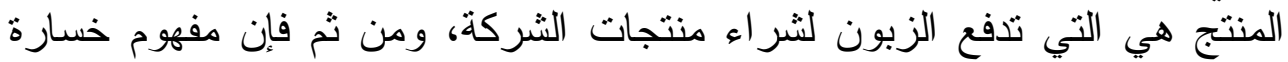

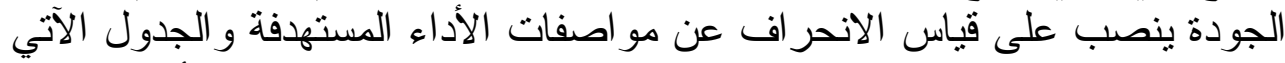

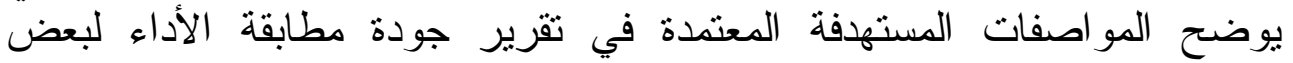
المنتجات التي ينتجها المصنع.

\begin{tabular}{|c|c|c|c|c|c|c|c|c|c|c|c|c|c|c|c|c|}
\hline \multicolumn{17}{|c|}{ الجدول ال } \\
\hline \multicolumn{8}{|c|}{ م مو اصفات الأداء للقماش المكمل } & \multicolumn{8}{|c|}{ مو اصفات الأداء للقماش الخام } & \multirow{3}{*}{ ورقماشه } \\
\hline \multicolumn{2}{|c|}{ الكثافة/ اسم } & \multicolumn{2}{|c|}{ الآكماش\% } & \multicolumn{2}{|c|}{ الاستطالة\%\% } & \multicolumn{2}{|c|}{ المتانة/كفم } & \multicolumn{2}{|c|}{ الكثافة/ اسم } & \multicolumn{2}{|c|}{ الانكماش\%\% } & \multicolumn{2}{|c|}{ الاسنطالة \% } & \multicolumn{2}{|c|}{ المتانة/كف } & \\
\hline J & س & J & س & J & س & J & 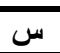 & $J$ & س - س & j & س & $J$ & س & $J$ & س & \\
\hline$\overline{r T}$ & ro & 0 & 0 & Tr & $\mathrm{v}$ & $\xi$. & $\sum 0$ & $\overline{r r}$ & $\overline{r r}$ & $r, 0$ & $0, \xi$ & $7, V$ & $\overline{T 1, r}$ & or & $\varepsilon r$ & همايون إب" \\
\hline 11 & To & $\cdot, 0$ & $\varepsilon, 0$ & $\Lambda$ & 7 & $r$. & 7. & 11 & $r \varepsilon$ & 0 & $\mathrm{v}$ & 7 & 9,0 & rq & $\pi$ & 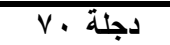 \\
\hline$\overline{T r}$ & $T \varepsilon$ & 0 & 0 & 1. & 7,0 & $r v$ & 00 & IT & $r \varepsilon$ & $\varepsilon$ & 7,0 & $\mathrm{~V}$ & $\mathrm{~V}$ & 01 & 7. & نوارس \\
\hline \multicolumn{8}{|c|}{ ليجهز خام اسمر } & $1 \varepsilon$ & IV & $\overline{0}$ & $\mathrm{v}$ & $\mathrm{v}, 0$ & $V, 0$ & ro & 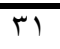 & 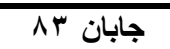 \\
\hline 10 & $T \varepsilon$ & $\bar{r}$ & $\varepsilon$ & 1 & 0 & TO & $r$. & $1 \varepsilon$ & Tr & $\Lambda$ & 7 & 7 & $\varepsilon$ & 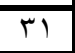 & r & رافدين 1 ري \\
\hline 17 & TO & $\bar{T}$ & $\bar{r}$ & $\mathrm{~V}$ & $\Lambda$ & $\varepsilon r$ & $\mathrm{v} \cdot$ & 17 & $\overline{r r}$ & T & T & $\mathrm{V}$ & $\Lambda$ & «1 & vo & بوبيلين \\
\hline 11 & ro & r & r & 7 & $\mathrm{v}$ & r. & $\mathrm{v} \cdot$ & 11 & Tr & 1 & 1 & 0 & $\mathrm{v}$ & tr & 07 & 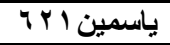 \\
\hline 17 & 19 & 1 & $r$ & v & 0 & $r \cdot$ & $r$ & 17 & 17 & $\varepsilon, 0$ & $r, 0$ & $\bar{v}$ & $\bar{v}$ & $r T$ & $r \varepsilon$ & صابرين Y / \\
\hline \multicolumn{8}{|c|}{ يجزهز خام اسمر } & 0 & $\Lambda$ & 0 & 0 & 0 & 0 & $r$ & 1. & شاش rrr \\
\hline \multicolumn{8}{|c|}{ يجهز خام اسمر } & $\mathrm{V}$ & IV & 0 & 0 & $r$ & $r$ & 0 & $r$. & باندج \& r 7 \\
\hline
\end{tabular}

\section{r إن خوات تطبيق دالة الخسارة}

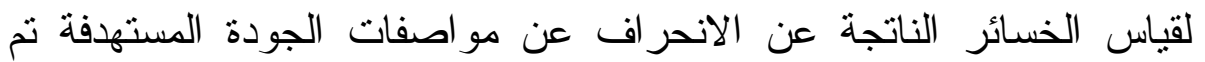

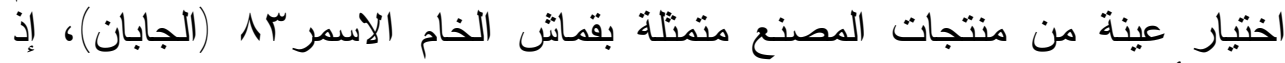

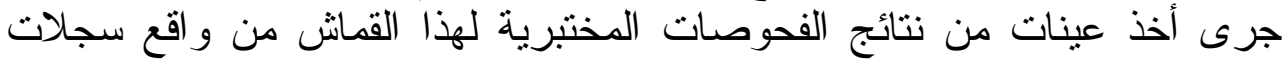

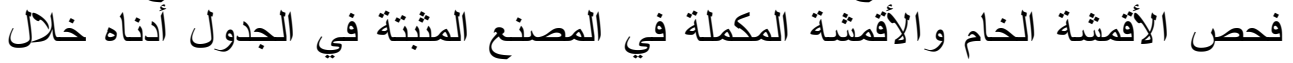

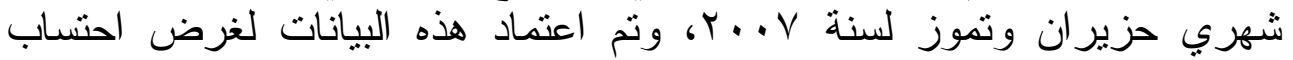
متغير ات الأنموذج باستخدام برنامج (Excel) وكما هو موضح بانه بالجدول الآتي: 


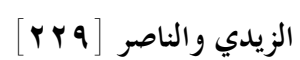

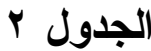

نتائج الفحوصات المختبرية لمواصفات جودة أداء القماش للمتر الطولي

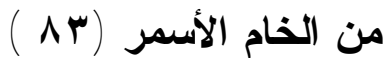

\begin{tabular}{|c|c|c|c|c|c|c|c|c|}
\hline \multicolumn{8}{|c|}{ مواصفات الأداء لقماش الخام الاسمر ب } & \multirow[b]{3}{*}{ 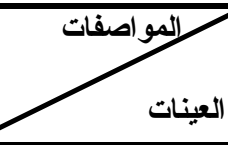 } \\
\hline \multicolumn{2}{|c|}{ الكثافة/ /سم } & \multicolumn{2}{|c|}{ الانكماش\% } & \multicolumn{2}{|c|}{ الاستطالة\% } & \multicolumn{2}{|c|}{ المتانة/كغم } & \\
\hline لحمة & سدى & لحمة & سدى & لحمة & سلى & لحمة & سدى & \\
\hline ir & 17 & 0 & 7,0 & 0 & $\varepsilon, 0$ & YT & rA & العينة | \\
\hline ir & IV & 0 & 7 & 0 & $\varepsilon, 0$ & r^ & MT & العينة r \\
\hline $1 \varepsilon$ & 10 & 0 & 7 & 7 & 0 & ro & $T V$ & العينة r \\
\hline 14 & 10 & $\varepsilon, 0$ & 7 & 0,0 & 0 & ro & $r \varepsilon$ & العينة ؛ \\
\hline Tr & 17 & 7 & $\Lambda$ & 0 & 0 & rT & $r \cdot$ & العينةه \\
\hline 14 & 17 & $\varepsilon$ & 7 & 0 & $\varepsilon$ & $r \wedge$ & TV & العينة 7 \\
\hline $1 \pi$ & IV & 0 & 7 & 7 & $\varepsilon, 0$ & rT & M & V V العينة V V \\
\hline $1 \leq$ & 17 & 0 & 7,0 & 0,0 & 0 & ro & $r \cdot$ & العينةم \\
\hline IY,AVO & 10,10 & $\varepsilon, 9 \mu V$ & 7, rVo & $0, r \vee 0$ & $\varepsilon, 7 \wedge \vee$ & $r_{\tau}, 1, r_{0}$ & $r_{\text {१, }, \wedge \vee ०}$ & الوسط الحسابي \\
\hline •,$\wedge r \leqslant 0$ & $\cdot, V \cdot V)$ & .,07r9 & $7,9 \leq \pi$ & $\cdot, \varepsilon \leqslant r r$ & $\cdot, r V Y$ & $1, r \leq 7$ & $r, \leq V \leq$ & الانحر اف المعياري \\
\hline
\end{tabular}

المصدر : من إعداد الباحثين بالاعتماد على سجلات الفحوصات اليومية للقماش الأسمر .

ويلخص الجدول السابق نتائج الفحوصات المختبرية لقماش الخام الاسمر

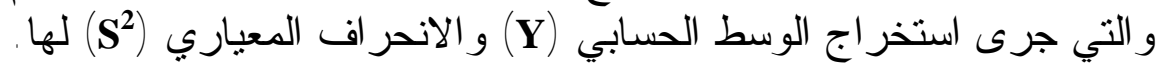

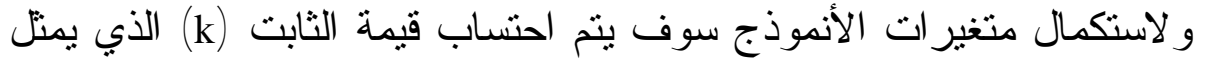

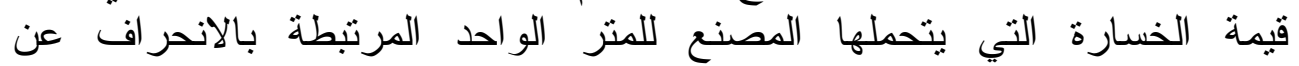
مو اصفات الجودة المستهدفة وكما هو موضح من خلال الجدول الآتي:

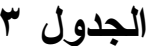

الجتساب متغير ات نموذج دالة خسارة الجودة (QLF)

\begin{tabular}{|c|c|c|c|c|c|c|c|c|}
\hline \multicolumn{2}{|c|}{ الكثافة } & \multicolumn{2}{|c|}{ الانكماش } & \multicolumn{2}{|c|}{ الاستطالة } & \multicolumn{2}{|c|}{ المتانة } & \multirow{2}{*}{ المو اصفة/ المتغيرات } \\
\hline J & س - ن س & J & س & J & س & J & س - ن س & \\
\hline- & - & 1 & $\wedge$ & - & - & - & - & الحد الأعلى منين القيمة \\
\hline ir & 10 & $\varepsilon$ & 1 & 0 & $\varepsilon$ & ro & TV & الحد الأدنى من القيمة \\
\hline $1 \varepsilon$ & iv & o & v & $v, 0$ & $\gamma, 0$ & ro & $r_{1}$ & القيمة المستهـفة T T \\
\hline- & - & 1 & 1 & - & - & - & - & المستهرفة الأعلي - القيمة \\
\hline r & r & 1 & 1 & $r, 0$ & $r, 0$ & 1. & $\varepsilon$ & القيمة المستهافة - الادنى (r-T)=T \\
\hline r & r & 1 & 1 & $r, 0$ & $r, 0$ & 1. & $\varepsilon$ & 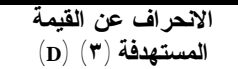 \\
\hline 1,0 & 1,0 & 1,0 & 1,0 & 1,0 & 1,0 & 1,0 & 1,0 & 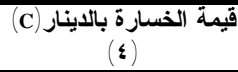 \\
\hline$\varepsilon, r_{0}$ & $\varepsilon, r_{O}$ & 1,0 & 1,0 & $r, \varepsilon$ & $r, \varepsilon r$ & $\cdot, 10$ & r, Iro & 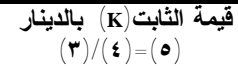 \\
\hline
\end{tabular}


تمتل قيم الحد الأعلى (U) والحد الأدنى (L) و القيمة المستهدفة (T)

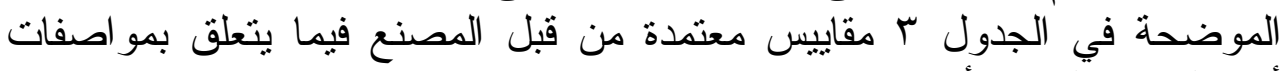

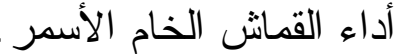

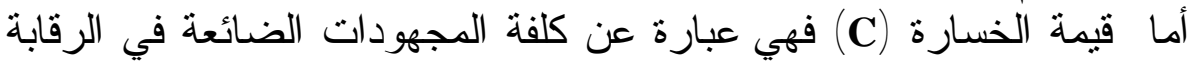

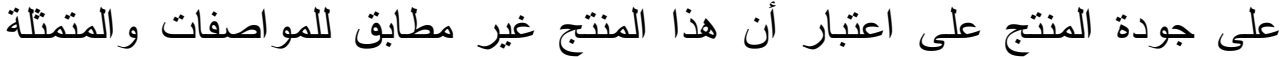

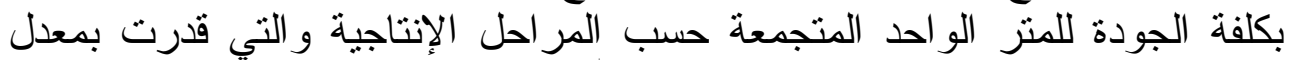

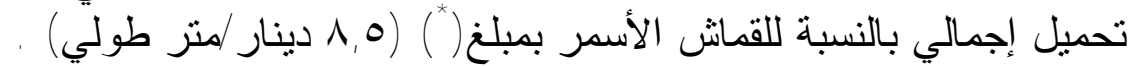

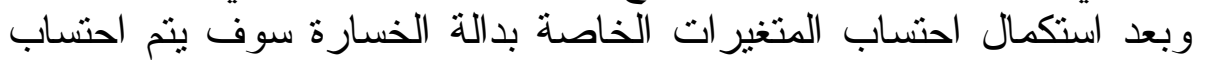

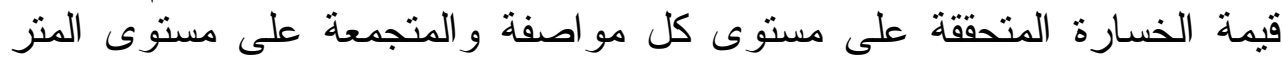
الطولي الواحد من قماش الخام الاسمر وكما هو موضح من خلال الجدول الآتي :

\begin{tabular}{|c|c|c|c|c|c|c|c|c|}
\hline \multicolumn{9}{|c|}{ الجدول ع } \\
\hline \multicolumn{2}{|c|}{ الكثَافة } & \multicolumn{2}{|c|}{ الأكماش } & \multicolumn{2}{|c|}{ الإستطالة } & \multicolumn{2}{|c|}{ المتانة } & \multirow{2}{*}{ المتونير اتفة } \\
\hline J & س & J & س & J & س & J & س & \\
\hline$\varepsilon, r_{0}$ & $\varepsilon, r_{O}$ & 1,0 & 1,0 & $r, \varepsilon$ & $r, \varepsilon r$ & $\cdot, 10$ & r, Iro & 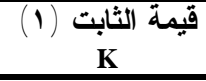 \\
\hline Ir,AVO & 10,10 & $\varepsilon, 9 r v$ & 7, rVo & $0, r^{\prime} 0$ & $\varepsilon, T \wedge V$ & $r 7,1 r_{0}$ & $r q, \wedge \vee 0$ & الحسابي (Y) \\
\hline$\cdot, \lambda r \leqslant 0$ & $\cdot, v \cdot V)$ &., $07 r 9$ & $7,9 \leqslant 4$ & $\cdot$, rVY & $\cdot$, TVY & $1, Y \leq 7$ & $r, \varepsilon V \varepsilon$ & 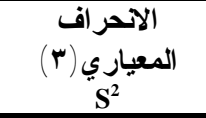 \\
\hline $1 \leq$ & iv & 0 & v & $v, 0$ & $v, 0$ & ro & r & 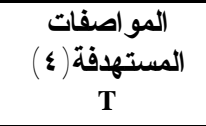 \\
\hline$\Lambda$, rイ & $\Lambda, r M V$ & 0, TITV & $(1, Y) \leqslant$ & $\Lambda, V+1$ & V,VTr & $\lambda, 7 \cdot r$ & $V, T \leq q$ & 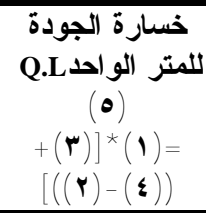 \\
\hline
\end{tabular}

المصدر : من إعداد الباحثين

ومن الجدول السابق يتبين بأن مقدار الخسارة المقدرة للمتر الطولي الواحد

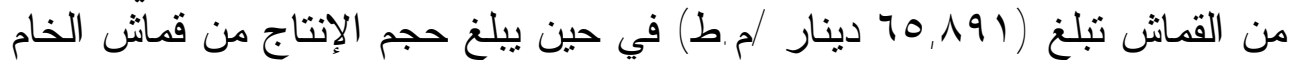

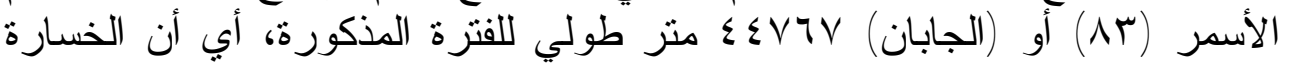

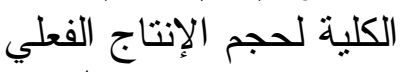
. 


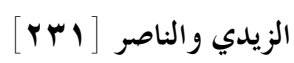

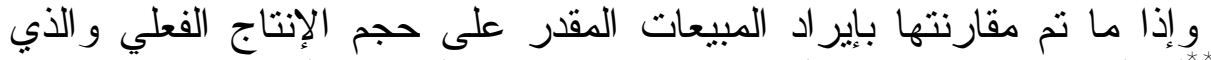

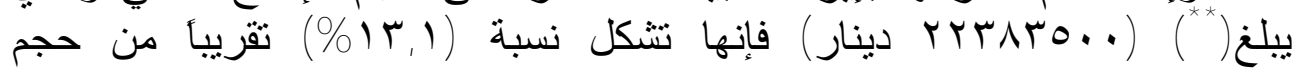
المبيعات .

\section{r ، مجالات استخدام معلومات دالة خسارة الجودة (QLF) في المصنع}

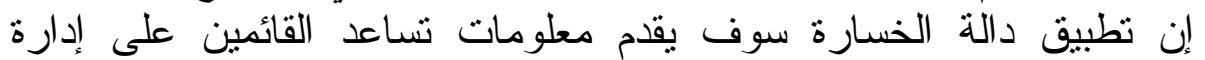

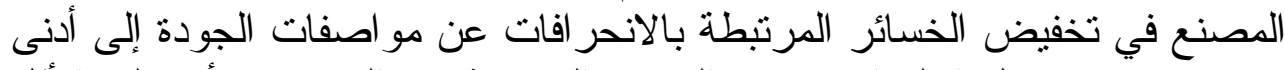

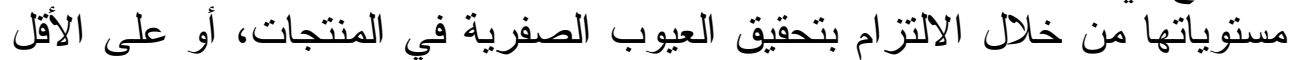

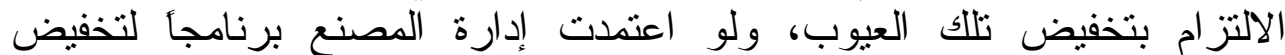

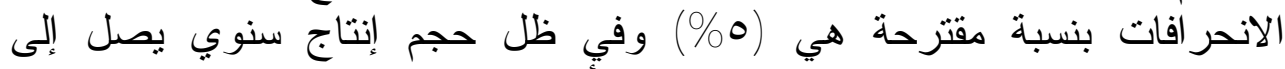

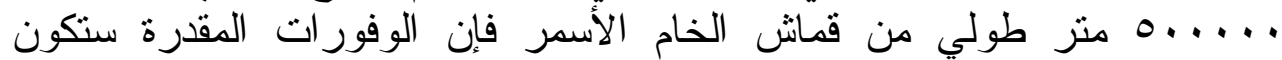

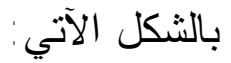

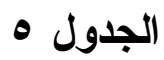

وفورات التكاليف المقدرة للتخفيض في نسبة الانحراف

\begin{tabular}{|c|c|c|c|c|c|c|}
\hline 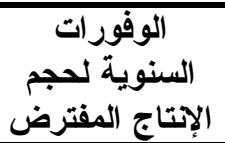 & وافورات التكاليف & خسارة الجودة & 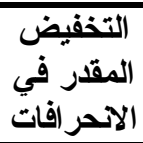 & خسارة الجودة الطوة للمتر & \multicolumn{2}{|c|}{ المو اصفات } \\
\hline $191 K \leqslant r$ & $\cdot, \Gamma \wedge Y \leq \Lambda$ & V,YTVY & $\% 0$ & $V, 7 \leq 9$ & س & \multirow[t]{2}{*}{ المتانة } \\
\hline$r 10.1$. & $\cdot, \leqslant T \cdot 17$ & $\Lambda, I \vee T, \varepsilon$ & $\% 0$ & $\Lambda, 7 \cdot r$ & J & \\
\hline $19 \pi 4 \leqslant 0$ & $\cdot, r \wedge 7791$ & $V, r \leqslant V \backslash Y \varepsilon$ & $\% 0$ & $V, V T r$ & س & \multirow[t]{2}{*}{ الاستطالة } \\
\hline rINTqV & $\cdot, \varepsilon 4709 \leqslant$ & $1,190 Y 9$ & $\% 0$ & $\Lambda, V M_{1}$ & $J$ & \\
\hline rᄉ. r To &., $07 . \mathrm{VT}$ & $1 \cdot, 70 \mathrm{rAV}$ & $\% 0$ & $11, r \mid \varepsilon$ & س & \multirow[t]{2}{*}{ الانكماش } \\
\hline 1 1rq11 & $\cdot$, r70八r & $0,0.1 \mathrm{~V}$ & $\% 0$ & $0, r, T V$ & $J$ & \\
\hline$r \cdot V q \leq r$ & $\cdot, \leqslant 10 \wedge \wedge$ & $v, 9 \cdot 111$ & $\% 0$ & $\Lambda, r \mid \vee$ & س & \multirow[t]{2}{*}{ الكثافة } \\
\hline$r .1199$ & $\cdot, \varepsilon 17499$ & $V, 9110 \mathrm{~V}$ & $\% 0$ & $\Lambda, r Y \Lambda$ & $J$ & \\
\hline
\end{tabular}

المصدر : من إعداد الباحثنين

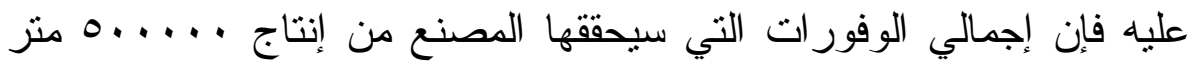

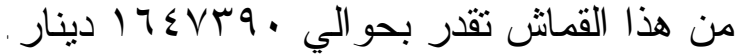

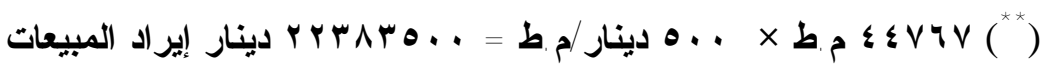


r. إن استخدام دالة خسارة الجودة (QLF) يعد أداة لتوجيه عمليات التخطيط

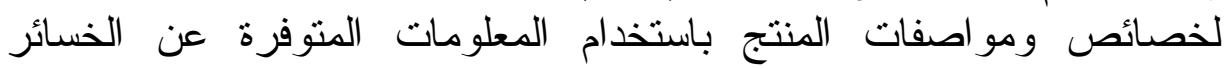

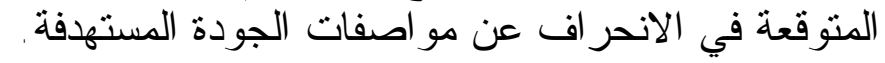

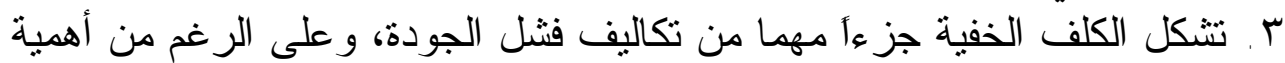

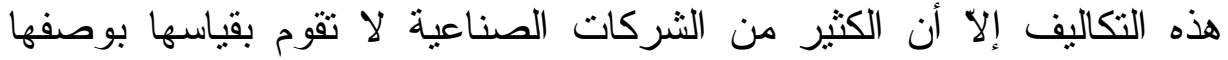
مقياسأ لاكتساب الفرصة الفان. ع . يعد تخفيض التكاليف من أهم المز ايا الني يمكن تحقيقها من تطبيق دالة خسارة الجودة (QLF) في الثركات الصناعية.

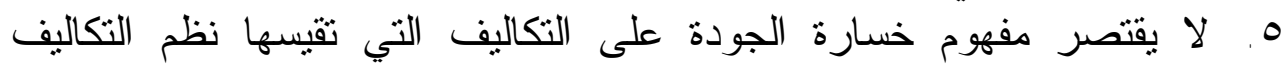

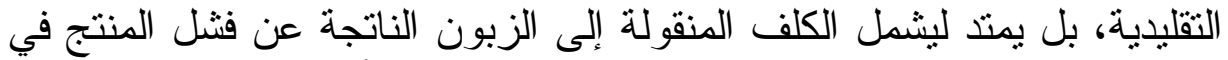
تحقيق نوقعات الزبون و الفنشل في تحقيق مو اصفات الأداء و الكلف الاجتماعية التية

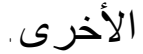

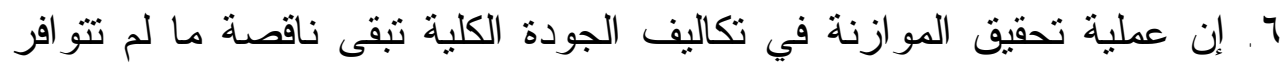

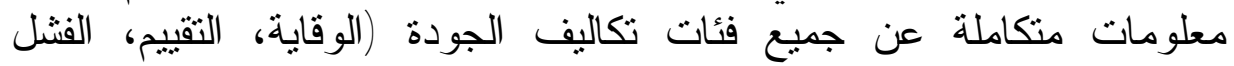

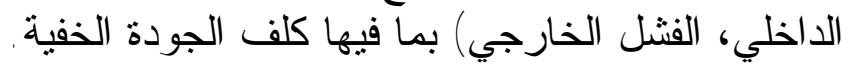

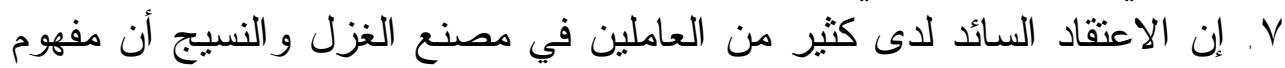
خسارة الجودة يقتصر على تكاليف المنتجات غير المين المطابقة للمو اصفات التئ التي ينت

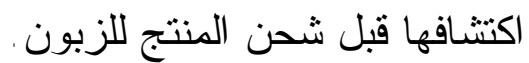

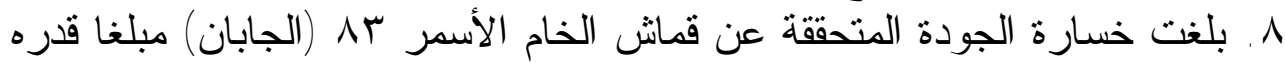

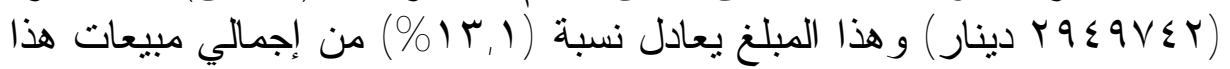

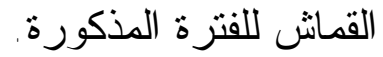

ثُانياً - التوصيات 1. الاهتمام بقياس التكاليف الخفية للابتعاد عن مواصيات التات الجودة المستهدفة

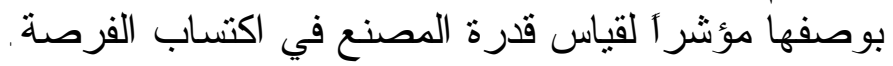

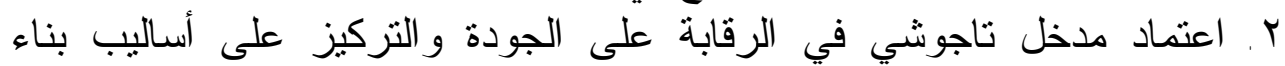

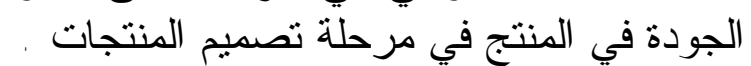

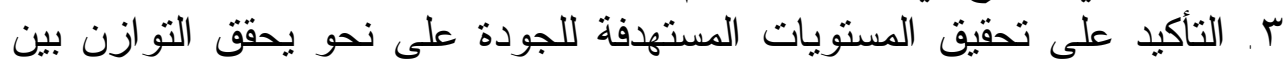

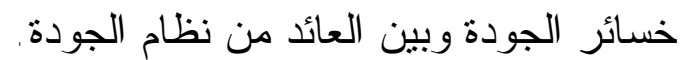

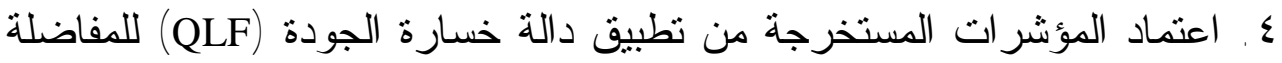

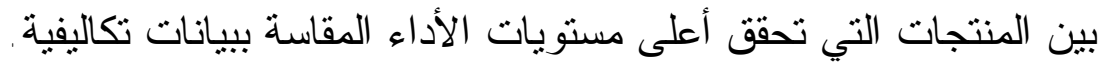

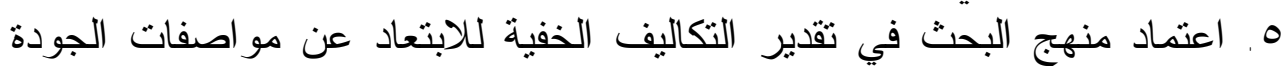
المستهدفة التي يتحملها المصنع من المنتجات الأخرى. 

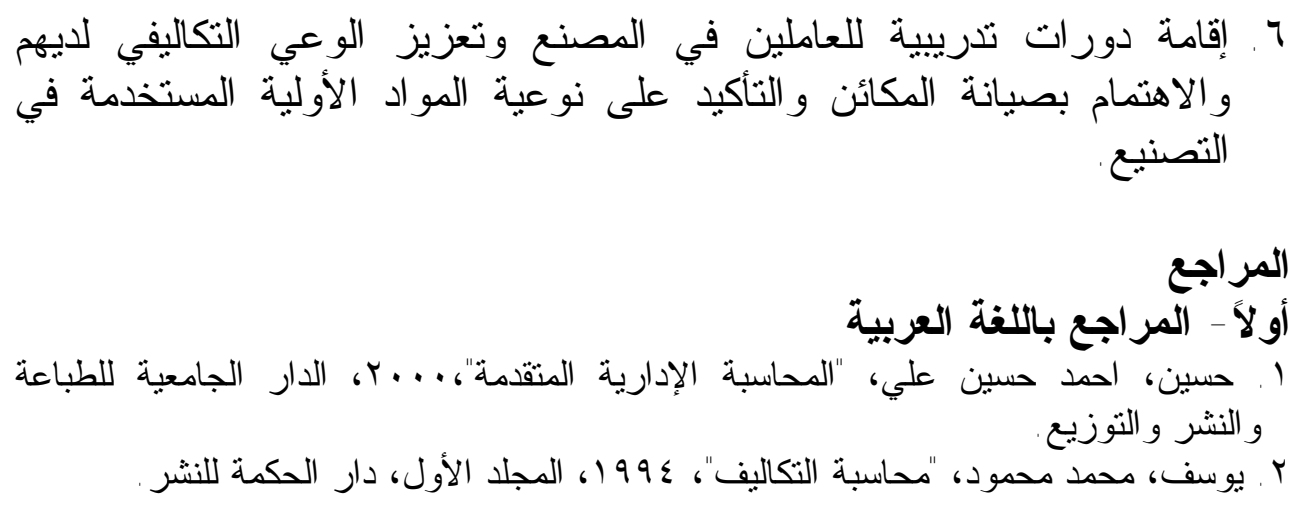

ثانياً - المر اجع باللغة الإجنبية

1. Albright, T. L, H.P. Roth,1994, "Managing quality through the quality loss function", Journal of cost management, (winter).

2. Albright, T., Roth H. ,1992, "The measurement of quality cost: An alternative paradigm", Accounting Horizons,(June).

3. Anderson, S., K .Sedatole,1998, " Designing quality into products :The use of accounting data in new product development ", Accounting Horizons, (September).

4. Barrie G. Dale,1994, " Managing Quality", Prentice Hall International .UK.limited.

5. Charles T. Horngren,2003, George Foster ,Srikant M. Datar, "Cost Accounting: A managerial emphasis", $10^{\text {th }}$ edition, prentice Hall international ,inc.

6. Fink Ross, 1993, "Quality Improvement technology using the taguchi method", The CPA Journal on-line.

7. Kim M ., Liao M. ,1994, "Estimating hidden quality cost with quality loss function", Accounting Horizons, (march).

8. Richard J. Schonberger, Edward M.Kond,1997, "operation management: customerfocused principles", McGraw Hill, new York

9. Sedatol, k., "the effect of measurement alternatives on non- financial quality measures: forward-looking properties",2003, accounting review, (April).

10. Taguchi G. ,D .Clausing, 1990, "Robust Quality", Harvard Business Review, (January).(www.maaw.info/index) 